\title{
Comparison of Different Methods of Urinary Protein Excretion Measurement: Is the King Really Dead?
}

\author{
Alicja Rydzewska-Rosołowska ${ }^{a}$ Katarzyna Kakareko ${ }^{a}$ Beata Naumnik ${ }^{b}$ \\ Tomasz Hryszko a \\ a2nd Department of Nephrology and Hypertension with Dialysis Unit, Medical University of \\ Białystok, Białystok, Poland; ${ }^{b}$ 1st Department of Nephrology and Transplantation with \\ Dialysis Unit, Medical University of Białystok, Białystok, Poland
}

\section{Keywords}

Proteinuria - Timed urine collection - Spot protein to creatinine ratio

\begin{abstract}
Introduction: Assessing proteinuria is of uttermost importance for a nephrologist. It is often indispensable to accurately quantify the amount of protein lost, hence complicated and timeconsuming urine collections (the gold standard or "king" of methods - 24-h protein excretion rate $[P E R]$ ) are often replaced by spot urinary protein to creatinine ratio (PCR). The aim of the study was to determine whether the latter can reliably compare to the gold standard and whether "timing" of a spot urine sample is essential. Methods: We performed a prospective, single-center study of 143 consecutive adult patients with glomerular proteinuria (a total of 187 cases). Protein and creatinine concentration was measured in 3 consecutive urine samples (starting with the first morning void) and a simultaneous $24-\mathrm{h}$ urine collection. Agreement between 24-h PER and PCR was evaluated with Bland-Altman plots. Results: Compared to PER 3 consecutive PCRs were $0.86,0.66$, and 0.50 higher with wide limits of agreement respectively. The bias between 2 methods was influenced by sex, CKD stage, albumin concentration and angiotensin-converting enzyme inhibitor/angiotensin receptor blocker treatment. In 24 participants, in whom at least 2 measurements at different time points were available, only $88 \%$ of differences were lower than the calculated repeatability coefficient. Conclusions: Unfortunately although random PCR correlates with 24-h protein excretion, the scatter of differences increases as $24-h$ proteinuria rises (without any significant effect of the sampling time). The observed lack of agreement makes PCR an unsuitable parameter to correctly quantify proteinuria; it is also not useful for monitoring the amount of daily proteinuria in the same patient. Therefore, while searching for new markers, nephrologists can only say: "long live the king!"

(c) 2019 The Author(s)

Published by S. Karger AG, Basel
\end{abstract}

Alicja Rydzewska-Rosołowska

2nd Department of Nephrology and Hypertension with Dialysis Unit

Curie-Sklodowskiej 24A

PL-15-276 Bialystok (Poland)

E-Mail alicja.rosolowska@umb.edu.pl 


\section{Kidney \\ Blood Pressure \\ Research}

\begin{tabular}{l|l}
\hline Kidney Blood Press Res 2019:44:993-1001 \\
\hline DOI: 10.1159/000501884 & $\begin{array}{l}\text { @ 2019 The Author(s). Published by S. Karger AG, Basel } \\
\text { www.karger.com/kbr }\end{array}$ \\
\hline
\end{tabular}

Rydzewska-Rosołowska et al.: Comparison of Different Methods of Urinary Protein Excretion Measurement: Is the King Really Dead?

\section{Introduction}

Normal urinary protein excretion is $<150 \mathrm{mg} /$ day. Detection and subsequent evaluation of the causes of proteinuria is one of the most common tasks performed everyday by nephrologists worldwide. All guidelines focus on the exact amount of protein excreted and therefore, it is of uttermost importance to accurately quantify proteinuria. For many years, 24-h urine collection was the "gold standard" or the "king" of methods although it is often a tiring chore for the patient, time-consuming, hard to perform outside of hospital, and even over- and under-collections happen. Therefore, for a long time, a quest for new methods of proteinuria quantification took place. In 1983, Ginsberg et al. [1] published a seminal paper on the use of single voided urine samples to estimate quantitative proteinuria. Quickly other publications followed showing a good correlation of spot protein to creatinine ratio (PCR) with 24-h protein excretion rate (PER). A single-center longitudinal study also proved that it might be a better predictor of kidney disease progression [2]. The excitement was only minimally suppressed by more recent data showing that although correlation is present, agreement between the tests might be poor and that both a diurnal and day-to-day variability in protein excretion exists [3].

Therefore, although an abundance of research is present, the question of how to quantify proteinuria remains valid. Citing KDIGO guidelines on glomerulonephritis (GN): there is currently insufficient evidence to preferentially recommend 24-h, shorter-timed or spot urine collections for proteinuria in the management of GN [4]. In contrast, non-nephrological guidelines: for example, American College of Rheumatology guidelines for lupus nephritis recommend that a spot urine protein/creatinine ratio of $>0.5$ can be substituted for the $24-\mathrm{h}$ protein measurement [5]. The main objective of the study was to compare the results of PCR and 24-h protein excretion and add to the discussion whether timing of a spot sample matters (as right now many physicians recommend using first morning void). Our hypothesis was that the agreement between spot PCR and 24-h PER is low.

\section{Material and Methods}

Study Design

We performed a prospective study between February 2017 and March 2018 at a university-based hospital in Bialystok, Poland.

\section{Participants}

Patients were recruited among individuals being hospitalized at that time at I Department of Nephrology and Transplantation. Eligibility was based on proteinuria on previous urinalysis. The inclusion criteria were age above 18, proteinuria above $0.5 \mathrm{~g} /$ day (based on earlier values, if during the hospitalization proteinuria was lower than $0.5 \mathrm{~g} /$ day patients were excluded from analysis), stable kidney function (less than $\pm 10 \%$ variation in estimated glomerular filtration rate), consent of the patient and whether the investigator deemed the patient capable of performing a complete 24-h urine collection. The exclusion criteria were dialysis, the presence of a Foley catheter, a urinary tract tumor and urinary tract infection, or inability to provide informed consent. Subjects formed a consecutive series.

\section{Test Methods}

The index test was spot PCR performed at 3 different time points. The reference standard was 24 -h protein excretion. Patients were given 3 spot urine containers clearly labeled with sample 1,2, and 3 and 24-h urine container. They were instructed to start the day by emptying 


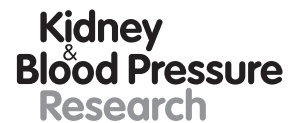

Research

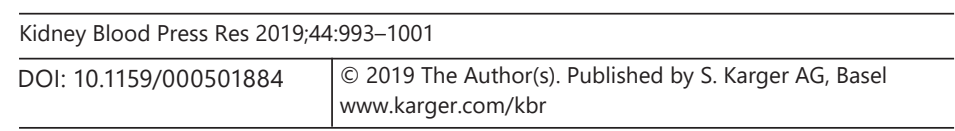

Rydzewska-Rosołowska et al.: Comparison of Different Methods of Urinary Protein Excretion Measurement: Is the King Really Dead?

the bladder into the toilet and afterwards into spot containers ( 3 consecutive samples of 20 $\mathrm{mL}$ into 3 consecutively labeled containers: PCR1, PCR2, PCR3) and the rest to another 24-h urine container. After 3 first micturitions, the patients were asked to urinate into the 24-h urine container only. The first void of the next morning was also included in the analysis. To ensure the accuracy of the 24-h urine collection, each patient received a written instruction together with an explanation of the procedure (around $15 \mathrm{~min}$ ) by one of 2 investigators (A.R.-R. or K.K.). During the day of collection, the investigators also checked the patient for compliance, the day after the collection, the patient was questioned once again about the completeness of the process - collections deemed incomplete were discarded from the analysis. All the samples were transferred immediately to hospital's accredited central laboratory and analyzed within $3 \mathrm{~h}$. Standard demographic data and relevant medical history including 24-h urine volume proteinuria cause (preferably biopsy-proven diagnosis), current angiotensin-converting enzyme inhibitor/angiotensin receptor blocker (ACEI/ARB), glucocorticoids or other immunosuppressive treatment, presence of a transplanted kidney or monoclonal protein in the urine, was collected by the investigators. Participants also underwent blood tests for creatinine (with estimated glomerular filtration rate estimation using the MDRD equation) and albumin in the same hospital laboratory. The spot urine protein and creatinine values were reported in $\mathrm{mg} / \mathrm{dL}$. Total measured urinary protein and creatinine excretion was reported in g/day. To once again assess the completeness of 24-h urine collection, creatinine excretion was also estimated using the formula reported by Ix et al. [6] - eCER $=879.89+12.51 \times$ weight $(\mathrm{kg})-6.19 \times$ age $+(34.51$ if black $)-(379.42$ if female).

Causes of proteinuria were classified into 3 categories: GN, diabetic nephropathy, and other (genetic diseases, unknown, renal involvement in plasma cell dyscrasias, hemolyticuremic syndrome, chronic allograft nephropathy). Clinical information was readily available to all study authors.

The study was approved by the Medical University of Bialystok Bioethics Committee (approval number R-I-002/174); all patients provided written consent.

\section{Analysis}

Medians and interquartile range are reported for continuous variables, and frequency and percentages for discrete data. Bland-Altman plots were used for evaluation of agreement between 24-h PER and PCR. Associations between variables of interest were explored with regression analysis. The reported $\beta$ and $p$ values depict the direction and the level of the statistical significance of the interaction. Differences between means were evaluated with ANOVA. The two-sided $p$ value below 0.05 was considered significant. Patients with missing data were omitted from the analysis (4 patients were excluded because 24-h proteinuria was missing). All statistical computations were done with Statistica 13.1 (Dell Inc., USA) and R version 3.3.3 (Vienna, Austria).

\section{Results}

\section{Participants}

Table 1 presents baseline characteristic of studied participants. Of the 143 participants of Caucasian origin, 24 had measurements done more than once, giving a total of 187 analyzed cases. Ages ranged from 18 to 82 years, with median 57 years. The distribution of chronic kidney disease stages was as follows: $16 \%$ in stage 1,13\% in stage 2, 32\% in stage 3, 27\% in stage 4 , and $13 \%$ in stage 5 . In 114 (61\%) cases steroids were used for the treatment of underlying kidney disease and therapy with ACEI/ARB was prescribed in 64 patients (34\%). 


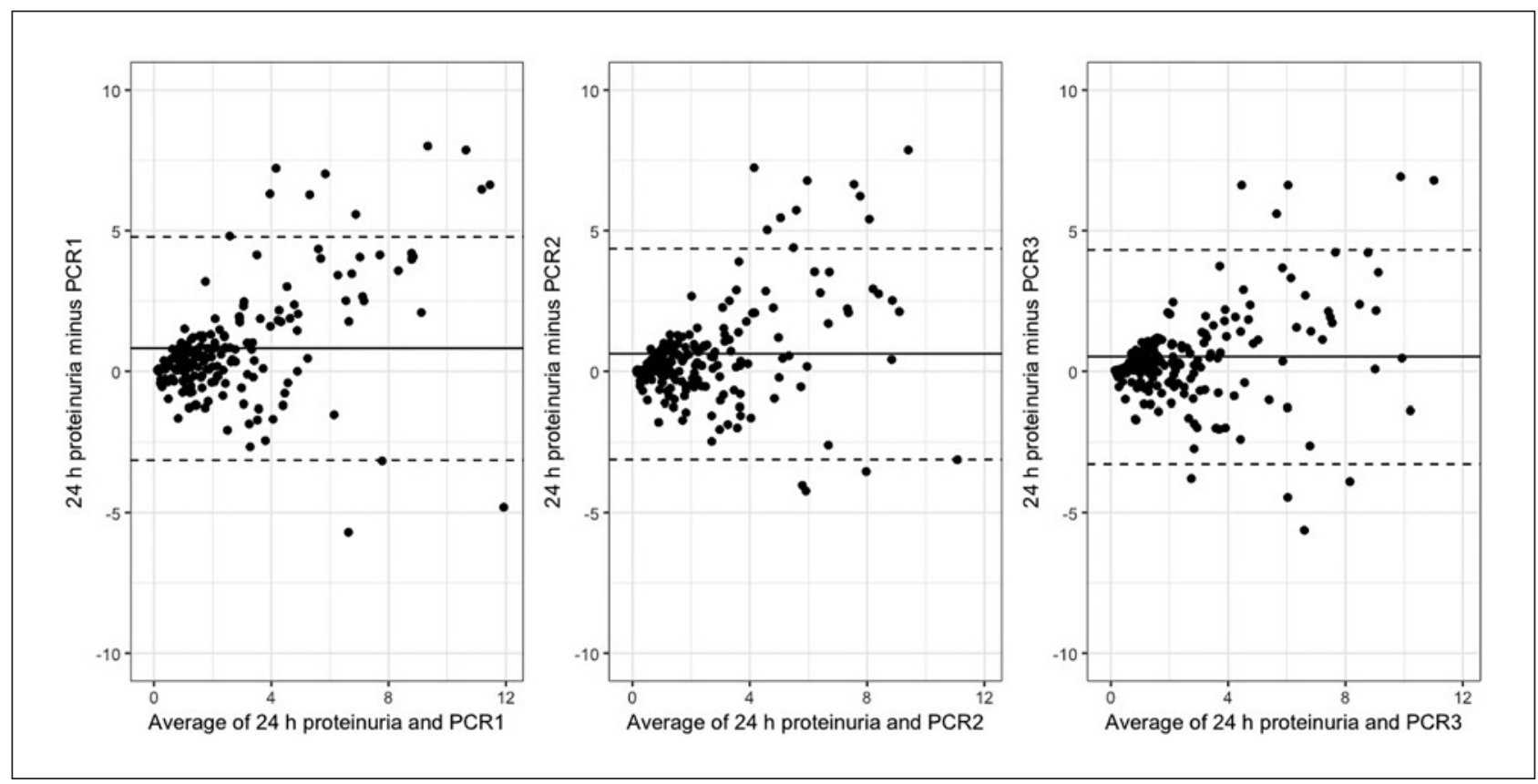

Fig. 1. The scatter of differences between 24-h proteinuria and spot PCR. PCR, protein to creatinine ratio.

\section{Agreement between Measured and Predicted Creatinine Excretion}

There was a linear correlation between measured and calculated values of creatinine excretion $(r=0.6, p<0.001)$ confirming the completeness of 24 -h urine collections.

\section{Relation between 24-h Proteinuria and PCR}

The scatter of differences increases as 24 -h proteinuria rises without any significant effect of the sampling time (Fig. 1). A logarithmic transformation decreased the relation between the mean proteinuria and the difference, but for the ease of interpretation analyzes of log-transformed data were abandoned. On average, 24-h proteinuria was higher than that predicted with PCR. The limits of agreement were wide (Table 2). The interquartile range of the bias and the percent of patients within acceptable range are presented in Table 3.

\section{Factors Influencing the Bias}

Regression analysis revealed the following significant associations between bias (difference between 24-h proteinuria and PCR) and sex (lower in females, $\beta=-0.23 p<0.01$ ), CKD stage (lower in more advanced stage, $\beta=-0.25 p<0.001$ ), albumin concentration (more pronounced in hypoalbuminemia, $\beta=-0.36 p<0.001$ ), treatment with ACEI/ARB (higher in treated persons, $\beta=0.16 p<0.05)$ but not BMI or use of steroids $(\beta=0.13 p=0.09)$.

To verify whether sampling of urine for PCR may introduce a bias to 24-h proteinuria, we performed the following calculations: First, we adjusted 24-h proteinuria for the amount of protein, which was lost due to PCR measurements (24-h proteinuria plus amount of protein in $20 \mathrm{~mL}$ taken for PCR measurement). Afterwards we compared newly calculated bias with the previous one and there were no significant differences.

We also performed a subgroup analysis according to 24 -h proteinuria, which confirmed increasing range in limits of agreement and the bias in line with the magnitude of protein excretion. Differences through the whole spectrum of daily proteinuria were unacceptable (Table 4). 
Kidney

Blood Pressure

Research

Table 1. Baseline characteristics of studied population

Table 2. Bias and the limits of agreement (and IQR) at different sampling times for PCR measurement

Table 3. Percentage of patients within acceptable range for 3 chosen "acceptable differences"

\begin{tabular}{l|l}
\hline Kidney Blood Press Res 2019;44:993-1001 \\
\hline DOI: 10.1159/000501884 & $\begin{array}{l}\text { (c) 2019 The Author(s). Published by S. Karger AG, Basel } \\
\text { www.karger.com/kbr }\end{array}$ \\
\hline
\end{tabular}

Rydzewska-Rosołowska et al.: Comparison of Different Methods of Urinary Protein Excretion Measurement: Is the King Really Dead?

\begin{tabular}{ll}
\hline Variable & Value \\
\hline Age, years, median (IQR) & $57(38-67)$ \\
Gender, male, $n$ (\%) & $75(40)$ \\
BMI, kg/m ${ }^{2}$, median (IQR) & $28(24-32)$ \\
Cause of proteinuria, $n$ (\%) & \\
$\quad$ Glomerulonephritis & $126(67)$ \\
$\quad$ Diabetic nephropathy & $24(13)$ \\
$\quad$ Other & $37(20)$ \\
Use of, $n$ (\%) & \\
$\quad$ ACEI/ARB & $123(66)$ \\
$\quad$ Steroids & $73(39)$ \\
eGFR MDRD, mL/min $/ 1.73$ m ${ }^{2}$, median (IQR) & $36.6(20.3-67.6)$ \\
Proteinuria, g/ 24 h, median (IQR) & $2.1(1.1-4.0)$ \\
Serum albumin, g/dL, median (IQR) & $3.56(2.98-3.93)$ \\
Hemoglobin, g/dL, median (IQR) & $12.3(10.5-13.7)$ \\
White blood cell count, $10^{9} / \mathrm{L}$, median (IQR) & $7.25(5.71-9.07)$ \\
Platelet count, $10^{9} / \mathrm{L}$, median (IQR) & $228(184-276)$ \\
\hline
\end{tabular}

IQR, interquartile range; ACEI/ARB, angiotensin-converting enzyme inhibitor/angiotensin receptor blocker; eGFR, estimated glomerular filtration rate.

\begin{tabular}{llll}
\hline Variable & Bias & $\begin{array}{l}\text { Limits of } \\
\text { agreement }\end{array}$ & IQR \\
\hline 24-h proteinuria, PCR1 & 0.86 & -3.18 to 4.90 & -0.11 to 1.30 \\
24-h proteinuria, PCR2 & 0.66 & -3.16 to 4.48 & -0.24 to 1.03 \\
24-h proteinuria, PCR3 & 0.50 & -3.06 to 4.06 & -0.26 to 1.03 \\
\hline
\end{tabular}

Differences between biases were evaluated with ANOVA and were insignificant.

IQR, interquartile ranges; PCR, protein to creatinine ratio.

\begin{tabular}{llll}
\hline Variable & $0.25 \mathrm{~g}$ & $0.50 \mathrm{~g}$ & $0.75 \mathrm{~g}$ \\
\hline PCR1 & 20 & 37 & 49 \\
PCR2 & 24 & 40 & 53 \\
PCR3 & 24 & 42 & 53 \\
\hline
\end{tabular}

PCR, protein to creatinine ratio.

\section{Repeatability of the Bias in the Same Patient}

Calculated repeatability coefficient was equal to $4.3 \mathrm{~g}$ per 24 -h in 24 participants, in whom at least 2 measurements at different time points were available. Only $88 \%$ of differences were less than the coefficient, what is below the threshold suggested by British Standard Institution. It shows that PCR is not a suitable parameter for monitoring the amount of daily proteinuria in the same patient. 


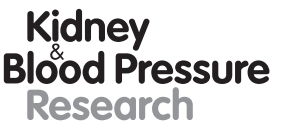

Kidney
Blood Pressure
Research

Table 4. Bias according to 24-h proteinuria (limits of agreement) [IQR]

\begin{tabular}{llll}
\hline Variable & $<1.0 \mathrm{~g}$ & $1-3.5 \mathrm{~g}$ & $>3.5 \mathrm{~g}$ \\
\hline PCR1 & $-0.13(-1.07$ to 0.81$)$ & $0.26(-1.62$ to 2.14$)$ & $2.5(-3.2$ to 8.2$)$ \\
& {$[-0.35$ to 0.13$]$} & {$[-0.14$ to 0.81$]$} & {$[1.03$ to 4.14$]$} \\
\hline PCR2 & $-0.20(-1.16$ to 0.76$)$ & $0.13(-1.65$ to 1.91$)$ & $2.1(-3.44$ to 7.64$)$ \\
& {$[-0.34$ to 0.10$]$} & {$[-0.36$ to 0.78$]$} & {$[0.42$ to 3.90$]$} \\
\hline PCR3 & $-0.27(-1.71$ to 1.17$)$ & $0.11(-1.81$ to 2.03$)$ & $1.66(-3.54$ to 6.86$)$ \\
& {$[-0.39$ to 0.08$]$} & {$[-0.41$ to 0.73$]$} & {$[0.49$ to 2.90$]$} \\
\hline
\end{tabular}

PCR, protein to creatinine ratio; IQR, interquartile range.

\section{Discussion}

Quantification of proteinuria is still a vital measurement for every single nephrologist. It has been argued that small differences do not matter [7], but according to guidelines [4], we base our treatment on certain values: for example, proteinuria above $4.0 \mathrm{~g}$ for membranous GN. Precision in quantification is therefore of uttermost importance, as it will guide almost the entire therapeutic process.

The gold standard of 24-hurine collection has long been discouraged as being cumbersome for the patient to perform and hard for the physician to interpret (the need to determine accuracy based on creatinine content) [8]. Spot urine testing is a tempting alternative, as it is simple and obtainable at once, eliminates the problem of "complete" collection and takes into account the influence of body size on proteinuria rate $[9,10]$.

The first paper to directly compare PCR with 24-h protein excretion was published in 1983 [1]. Only 46 patients took part in the study, and all spot samples were analyzed and the correlation coefficient was highly significant $(r=0.97)$. Other researchers report correlation coefficients ranging from 0.56 to 0.98 [11, 12]. A seminal study from Remuzzi group found not only a significant correlation between PCR and both absolute and log-transformed 24-h urinary protein values but also that PCR was a reliable predictor of progression of disease in a cohort of 98 non-diabetic patients followed up for 5 years [2]. Similar results were obtained in diabetic patients: in a cohort of 229 people with diagnosed type 1 diabetic nephropathy, a random urine PCR correlated with 24-h urinary protein [13].

When 2 methods are compared, however, neither the correlation coefficient (as was reported in studies cited above) nor regression analysis are appropriate, but the degree of agreement should be addressed, as pointed out by Bland and Altman [14]. Our study clearly demonstrates that unfortunately although random PCR correlates with 24-h protein excretion, the scatter of differences increases as 24 -h proteinuria rises (without any significant effect of the sampling time). On average, 24-h proteinuria was higher than when determined from PCR, but the limits of agreement were wide. Of note, irrespective of whether sub-nephrotic or nephrotic patients were analyzed, the differences were unacceptably high (the usually good correlation between PCR and 24-h PER is partly explained as a mathematical consequence of comparing both over a wide value range, so PCR is perceived as a better measure in nephrotic patients and less specific in proteinuria below $3.5 \mathrm{~g}$ /day). The observed lack of agreement opposes an earlier study where, applying the Bland-Altman test to a cohort of 170 proteinuric patients, a good correlation and precision of agreement was demonstrated for both methods (PCR and 24-h PER) [15]. 


\section{Kidney \\ Blood Pressure \\ Research}

\begin{tabular}{l|l}
\hline Kidney Blood Press Res 2019;44:993-1001 \\
\hline DOI: 10.1159/000501884 & $\begin{array}{l}\text { ○ 2019 The Author(s). Published by S. Karger AG, Basel } \\
\text { www.karger.com/kbr }\end{array}$ \\
\hline
\end{tabular}

Rydzewska-Rosołowska et al.: Comparison of Different Methods of Urinary Protein Excretion Measurement: Is the King Really Dead?

Factors correlating with the bias (the extent of lack of agreement) were female sex, CKD stage, hypoalbuminemia, and ACEI/ARB treatment but not BMI or glucocorticoid treatment. Those differences might be partly explained by creatinine excretion (lower in females and advanced CKD stages, so if on average the 24-h proteinuria is higher, in those patients with a lower denominator in PCR, as shown in our study the bias would be lower), although there was no correlation with the BMI or glucocorticoid use -2 factors that also influence creatinine generation and excretion. Based on those factors, we developed a prediction equation (which included sex, age, weight, and serum albumin concentration) to estimate daily proteinuria, that yielded slightly better results, although we do not think that it is valuable in everyday situations as it would be relatively complicated and time consuming.

During the last decade, clinical observations and small studies suggested the above, for example, in lupus nephritis a meta-analysis of 13 studies concluded that results of 24-h PER and PCR show poor agreement between both tests [16]. In 2016 Hogan et al. [17] published an observation from the NEPTUNE cohort (Nephrotic Syndrome Study Network) of 302 adult and pediatric patients. The correlation between random PCR and 24-h PER was moderate, although $\log _{10}$ transformation of values strengthened it. The authors also developed a prediction equation (based on logarithmic transformation), which further improved precision. The limitations of the above cited study was that PERs varied between validation cohort and derivation samples, 24-h urine collection was not directly observed (the yielded creatinine values were systematically lower than expected for adults), and the cohort consisted mainly of patients with focal and segmental glomerulosclerosis, minimal change disease and membranous nephropathy, so it is hard to generalize the results.

The relatively new aspect of our study is that we also (although on a small group of 24 patients) were able to show that there was no repeatability of the bias in the same patient, which suggests, in opposition to expert recommendations [18] that PCR is not a suitable parameter for monitoring the amount of daily proteinuria in the same patient. In literature, the above fact was reported in lupus nephritis only, when during longitudinal observation (15 months) of 103 lupus nephritis patients 59\% of PCR values were "problematic" or "unreliable" [19].

The undisputable strength of our study is that the 24-h urine collections were performed in one center and every patient was directly observed by 2 of the authors (A.R.-R. and K.K.). The other is that both the spot PCR and the 24-h urine collections were made on the same day. Taking into account diurnal variation in protein excretion, we collected 3 spot PCRs, therefore also testing the assumption that one spot sample is better than the other. We included different causes of proteinuria in our analysis (although we excluded non-glomerular proteinuria) so the results could be generalized - we wanted to re-create a real-life situation, as nephrologists treat all those proteinuric patients. We also included subjects with a wide range of proteinuria: from $500 \mathrm{mg}$ up to $>10 \mathrm{~g} /$ day.

We are aware of the limitations of this study. First of all we measured protein not albumin excretion, although that is what is usually done in real-life situations and that is what was studied in most trials. Second, patients participating in our study reflected practically all stages of CKD. One could argue that could be the cause of low agreement but analyzing the results there were no differences in the extent of bias when only patients with CKD 1 and 2 were included. Studies proving a highly significant correlation between PCR and 24-h PER also included those with normal renal function or mild, moderate, and severe renal dysfunction [20].

In conclusion, we show that spot PCR is not a reliable parameter, neither for initial qualification of proteinuria nor for follow-up measurements of protein excretion (as suggested by experts) [18]. We can only quote Roger Rodby and the French (although supporting an opposite point of view) "Le roi est mort, vive le roi!" - the spot urine collection is dead [7]. Unfortunately, for now, only 24-h urine collections remain for accurate protein excretion measurement. 


\section{Acknowledgment}

No acknowledgments.

\section{Statement of Ethics}

Research was conducted in accordance with the Declaration of Helsinki.

\section{Disclosure Statement}

Authors declare that they have no conflicts of interest to disclose.

\section{Funding Sources}

No funding was obtained for this review.

\section{Author Contributions}

A.R.-R., K.K., and T.H.: research idea and study design. A.R.-R., K.K.: data acquisition. A.R.-R., K.K., and T.H.: data analysis/interpretation. T.H.: statistical analysis. T.H. and B.N.: supervision or mentorship. Each author contributed important intellectual content during manuscript drafting or revision and accepts accountability for the overall work by ensuring that questions pertaining to the accuracy or integrity of any portion of the work are appropriately investigated and resolved.

\section{References}

1 Ginsberg JM, Chang BS, Matarese RA, Garella S. Use of single voided urine samples to estimate quantitative proteinuria. N Engl J Med. 1983 Dec;309(25):1543-6.

2 Ruggenenti P, Gaspari F, Perna A, Remuzzi G. Cross sectional longitudinal study of spot morning urine protein:creatinine ratio, 24 hour urine protein excretion rate, glomerular filtration rate, and end stage renal failure in chronic renal disease in patients without diabetes. BMJ. 1998 Feb;316(7130):504-9.

3 Naresh CN, Hayen A, Craig JC, Chadban SJ. Day-to-day variability in spot urine protein-creatinine ratio measurements. Am J Kidney Dis. 2012 Oct;60(4):561-6.

4 Kidney Disease: Improving Global Outcomes (KDIGO) Glomerulonephritis Work Group. KDIGO Clinical Practice Guideline for Glomerulonephritis. Kidney Int Suppl. 2012;2:139-274.

5 Hahn BH, McMahon MA, Wilkinson A, Wallace WD, Daikh DI, Fitzgerald JD, et al.; American College of Rheumatology. American College of Rheumatology guidelines for screening, treatment, and management of lupus nephritis. Arthritis Care Res (Hoboken). 2012 Jun;64(6):797-808.

6 Ix JH, Wassel CL, Stevens LA, Beck GJ, Froissart M, Navis G, et al. Equations to estimate creatinine excretion rate: the CKD epidemiology collaboration. Clin J Am Soc Nephrol. 2011 Jan;6(1):184-91.

7 Rodby RA. Timed Urine Collections for Albumin and Protein: “The King Is Dead, Long Live the King!". Am J Kidney Dis. 2016 Dec;68(6):836-8.

8 Wilmer WA, Rovin BH, Hebert CJ, Rao SV, Kumor K, Hebert LA. Management of glomerular proteinuria: a commentary. J Am Soc Nephrol. 2003 Dec;14(12):3217-32.

9 Shidham G, Hebert LA. Timed urine collections are not needed to measure urine protein excretion in clinical practice. Am J Kidney Dis. 2006 Jan;47(1):8-14.

10 Gaspari F, Perico N, Remuzzi G. Timed urine collections are not needed to measure urine protein excretion in clinical practice. Am J Kidney Dis. 2006 Jan;47(1):1-7. 
11 Dyson EH, Will EJ, Davison AM, O'Malley AH, Shepherd HT, Jones RG. Use of the urinary protein creatinine index to assess proteinuria in renal transplant patients. Nephrol Dial Transplant. 1992;7(5):450-2.

12 Price CP, Newall RG, Boyd JC. Use of protein:creatinine ratio measurements on random urine samples for prediction of significant proteinuria: a systematic review. Clin Chem. 2005 Sep;51(9):1577-86.

13 Rodby RA, Rohde RD, Sharon Z, Pohl MA, Bain RP, Lewis EJ; The Collaborative Study Group. The urine protein to creatinine ratio as a predictor of 24-hour urine protein excretion in type 1 diabetic patients with nephropathy. Am J Kidney Dis. 1995 Dec;26(6):904-9.

14 Bland JM, Altman DG. Statistical methods for assessing agreement between two methods of clinical measurement. Lancet. 1986 Feb;1(8476):307-10.

15 Chitalia VC, Kothari J, Wells EJ, Livesey JH, Robson RA, Searle M, et al. Cost-benefit analysis and prediction of 24-hour proteinuria from the spot urine protein-creatinine ratio. Clin Nephrol. 2001 Jun;55(6):436-47.

16 Medina-Rosas J, Yap KS, Anderson M, Su J, Touma Z. Utility of Urinary Protein-Creatinine Ratio and Protein Content in a 24-Hour Urine Collection in Systemic Lupus Erythematosus: A Systematic Review and MetaAnalysis. Arthritis Care Res (Hoboken). 2016 Sep;68(9):1310-9.

17 Hogan MC, Reich HN, Nelson PJ, Adler SG, Cattran DC, Appel GB, et al. The relatively poor correlation between random and 24-hour urine protein excretion in patients with biopsy-proven glomerular diseases. Kidney Int. 2016 Nov; 90(5):1080-9.

18 Rovin BH. Assessment of urinary protein excretion and evaluation of isolated non-nephrotic proteinuria in adults. In: Lam AQ, editor. UpToDate; 2019.

19 Shidham G, Ayoub I, Birmingham D, Hebert P, Rovin B, Diamond B, et al. Limited Reliability of the Spot Urine Protein/Creatinine Ratio in the Longitudinal Evaluation of Patients With Lupus Nephritis. Kidney Int Rep. 2018 Apr;3(5):1057-63.

20 Morales JV, Weber R, Wagner MB, Barros EJ. Is morning urinary protein/creatinine ratio a reliable estimator of 24-hour proteinuria in patients with glomerulonephritis and different levels of renal function? J Nephrol. 2004 Sep-Oct;17(5):666-72. 